\title{
AS ALTERAÇõES PROMOVIDAS PELA L'1EI 12.760/2012
}

\section{Paulo Roberto Batista}

Aceitar outras provas admitidas no direito para a comprovação do crime de embriaguez ao volante e transformá-lo em crime de perigo abstrato motivaram a alteração do Código de Trânsito Brasileiro pela redação da Lei no 12.760/2012. Esta veio alterar o art. 306 do CTB trazendo uma nova pespectiva para a apuração do crime de embriaguez ao volante, conforme se depreende do texto abaixo:

Art. 306. Conduzir veículo automotor com capacidade psicomotora alterada em razão da influência de álcool ou de outra substância psicoativa que determine dependência: (Redação dada pela Lei no 12.760, de 2012)

Penas - detenção, de seis meses a três anos, multa e suspensão ou proibição de se obter a permissão ou a habilitação para dirigir veículo automotor.

$\S 1^{\circ}$ As condutas previstas no caput serão constatadas por: (Incluído pela Lei no 12.760, de 2012)

I - concentração igual ou superior a 6 decigramas de álcool por litro de sangue ou igual ou superior a 0,3 miligrama de álcool por litro de ar alveolar; ou (Incluído pela Lei no 12.760, de 2012)

II - sinais que indiquem, na forma disciplinada pelo Contran, alteração da capacidade psicomotora. (Incluído pela Lei no 12.760, de 2012)

$\S 2^{\circ}$ A verificação do disposto neste artigo poderá ser obtida mediante teste de alcoolemia ou toxicológico, exame clínico, perícia, vídeo, prova testemunhal ou outros meios de prova em direito admitidos, observado o direito à contraprova. (Redação dada pela Lei no 12.971, de 2014)

\footnotetext{
${ }^{1}$ Servidor Público. Bacharel em Direito e Graduado em Gestão e Educação para o Trânsito. Pós-graduado em Ciências do Trânsito. Especialista em Ciências do Trânsito; Políticas Públicas do Trânsito; Segurança Pública; Direito Penal e Processo Penal.
} 
$\S 3^{\circ}$ O Contran disporá sobre a equivalência entre os distintos testes de alcoolemia ou toxicológicos para efeito de caracterização do crime tipificado neste artigo. (Redação dada pela Lei no 12.971, de 2014) ${ }^{2}$ (grifo nosso)

Notam-se duas importantes inovações que merecem destaque. A primeira delas diz respeito ao enfrentamento de o que é a capacidade psicomotora alterada e, a segunda, qual a maneira se de se produzir as outras provas admitidas em direito.

A Resolução no 206 do Conselho Nacional de Trânsito foi o primeiro norte orientador para a sondagem da alteração da capacidade psicomotora alterada. A Resolução no 432, que a sucedeu, traz o modelo de um termo de constatação ${ }^{3}$. Nesse sentido, a fim de se constatar a capacidade psicomotora alterada, alguns aspectos são conjuntamente observados, por exemplo, se o condutor aparenta sonolência, olhos vermelhos, vômitos, soluços, desordem nas vestes, odor de álcool no hálito, se possui atitude agressiva, arrogância, exaltação, ironia, dispersão e ainda o sentido de orientação (se o conduto sabe onde está, se sabe a data e a hora, dentre outros) ${ }^{4}$. A partir dessas características, em que pese o agente da autoridade de trânsito não ser perito, ele pode atestar pela embriaguez do condutor.

Segundo a Lei no 12.760/12, norma vigente, parece ser claro que o crime de embriaguez ao volante é de mera conduta e de perigo de dano em abstrato. É dispensável, portanto, o teste do bafômetro em face de serem admitidas todas

2 BRASIL. Lei no 9.503, de 23 de setembro de 1997. Institui o Código de Trânsito Brasileiro. Disponível em: <http://www.planalto.gov.br/ccivil_03/LEIS/L9503.htm>. Acesso em: 18 nov.. 2017.

3 BRASIL. Conselho Nacional de Trânsito. Resolução no 432, de 23 de novembro de 2013. Dispõe sobre os procedimentos a serem adotados pelas autoridades de trânsito e seus agentes na fiscalização do consumo de álcool ou de outra substância psicoativa que determine dependência, para aplicação do disposto nos arts. 165, 276, 277 e 306 da Lei no 9.503, de 23 de setembro de 1997 - Código de Trânsito Brasileiro (CTB). Disponível em: <https://www.legisweb.com.br/ legislacao/?id=250598 >. Acesso em: 18 nov.. 2017.

4 BRASIL. Conselho Nacional de Trânsito. Resolução no 432, de 23 de novembro de 2013. Dispõe sobre os procedimentos a serem adotados pelas autoridades de trânsito e seus agentes na fiscalização do consumo de álcool ou de outra substância psicoativa que determine dependência, para aplicação do disposto nos arts. 165, 276, 277 e 306 da Lei no 9.503, de 23 de setembro de 1997 - Código de Trânsito Brasileiro (CTB). Disponível em: <https://www.legisweb.com.br/ legislacao/?id=250598 >. Acesso em: 18 nov.. 2017. 
as provas admitidas no direito. Também não há o que se falar quanto à hierarquia das provas ${ }^{5}$, pois, segundo Vicente Greco Filho, cada prova tem um valor e o juiz fica "vinculado dosimetricamente às provas apresentadas", mas ao livre convencimento motivado do juiz ${ }^{6}$. Assim, todas as provas devem ser sobrepesadas a fim de contribuírem com a convicção do magistrado. Vicente Greco Filho, também esclarece que por esse sistema o juiz tem a liberdade de apreciação, todavia, vincula o seu convencimento com o material probatório presente nos autos.

A recusa de se submeter ao teste do etilômetro para não ser responsabilizado criminalmente, sob o manto do comando supralegal de não ser obrigado a produzir prova contra si mesmo, não mais prospera. Isto porque o Estado, por intermédio dos seus agentes, pode usar os outros meios de prova disponíveis para a comprovação do crime de embriaguez, conforme preleciona o artigo 306 do Código de Trânsito Brasileiro.

O fato do suposto infrator não ter obrigação de produzir prova contra si não desobriga o Estado de promover a persecução penal usando outros meios de prova disponíveis no direito. Tudo nos termos da legislação vigente como se infere dos diplomas legais transcritos abaixo:

\section{Resolução № 75 CETRAN RS \\ DOS MEIOS DE PRODUÇÃO DE PROVA}

Art. $7^{\circ} \mathrm{O}$ meio de produção de prova da confirmação da alteração da capacidade psicomotora em razão da influência de álcool ou de outra substância psicoativa que determine dependência, observado o respeito às provas em direito admitidas, pode se dar por ação, iniciativa ou meio da própria administração pública, de particular, de agente da autoridade de trânsito ou veículo de imprensa. ${ }^{7}$

GREGO FILHO, Vicente. Manual de Processo Penal. 11. ed. São Paulo: Saraiva, 2015.p.236.

${ }^{6}$ GREGO FILHO, Vicente. Manual de Processo Penal. 11. ed. rev e atual. São Paulo: Saraiva, 2015. p.236.

7 RIO GRANDE DO SUL. Conselho Estadual de Trânsito. Resolução no 75/2013. Dispõe sobre os procedimentos a serem adotados pelas autoridades de trânsito e seus agentes na fiscalização do consumo de álcool ou de outra substância psicoativa que determine dependência, para aplicação do disposto nos arts. 165, 276, 277 e 306 da Lei no 9.503, de 23 de setembro de 1997 - Código de Trânsito Brasileiro (CTB), em complementação à 
Dessa forma, destaca-se que até as mídias produzidas pela imprensa podem servir como prova, ficando claro o objetivo de se alargar o universo probatório possível de ser utilizado pelos agentes públicos, isto é, não somente o tradicional etilômetro.

\section{DO TESTE DE ETILÔMETRO}

Art. 8․ O etilômetro deve atender aos seguintes requisitos:

I - ter seu modelo aprovado pelo INMETRO;

II - ser aprovado na verificação metrológica inicial, eventual, em serviço e anual realizada pelo Instituto Nacional de Metrologia, Qualidade e Tecnologia - INMETRO ou por órgão da Rede Brasileira de Metrologia Legal e Qualidade - RBMLQ;

Art. 9․ Deverá ser descontada do resultado do etilômetro (medição realizada) a margem de tolerância, que será o erro máximo admissível, conforme legislação metrológica, de acordo com a "Tabela de Valores Referenciais para Etilômetro" constante no Anexo I da Resolução no 432/2013 do CONTRAN.

Parágrafo Único. O erro máximo admitido é o valor estabelecido pela legislação metrológica, que normatiza o uso e validade do equipamento, que diz respeito à capacidade de precisão do equipamento. ${ }^{8}$

Dentre os outros meios de provas possíveis, destacam-se as provas obtidas por intermédio da imagem, vídeo e áudio, ainda sem prejuízo de outras provas admitidas no direito. Fazendo-se uma interpretação extensiva ${ }^{9}$, conclui-se que tais provas não compõem um rol taxativo, mas meramente exemplificativo.

Resolução no 432/2013 do CONTRAN, e dá outras providências. Disponível em: $<$ http://www.cetran.rs.gov.br/upload/20130621101604

resolucao_75_procedimentos_para_fiscalizacao_165.pdf>. Acesso em: 18 nov.. 2017.

8 RIO GRANNDE DO SUL. Conselho Estadual de Trânsito. Resolução no 75/2013. Disponível em: <http://www.cetran.rs.gov.br/upload/20130621101604resolucao_75__procedimentos_para fiscalizacao_165.pdf>. Acesso em: 18 nov.. 2017.

9 Dar-se interpretação extensiva quando a Lei precisa ser ampliada, ou seja, diz menos do que deveria dizer. Desta forma, o intérprete deve observar quais os reais limites da norma. 
Art. 18. A prova de alteração do estado psicomotor do condutor pode ser obtida por qualquer meio tecnológico que permita registro ou gravação de filme, vídeo, fotografia e áudio.

Parágrafo único. Também pode ser obtida prova de alteração do estado psicomotor de condutor através de registro de áudio no qual se retrate o uso da linguagem falada, produzida pelo condutor, em demonstração da alteração da capacidade psicomotora quanto ao exercício da linguagem falada. ${ }^{10}$

Os recursos e meios de provas podem ser de propriedade da administração ou mesmo do agente da autoridade de trânsito que, por iniciativa própria, pode registrar vídeos, fotos e imagens. Deve-se, entretanto, ter zelo com tais registros a fim de garantir os direitos individuais de imagem do infrator, conforme o artigo abaixo:

Art. 19. O equipamento, para a obtenção da prova, pode ser disponibilizado pelo administrado, pelos veículos de imprensa, pela própria administração pública ou por equipamento de uso pessoal de agente da autoridade de trânsito.

$\S 1$ 1․ A utilização de equipamento de registro de imagem, vídeo e áudio, de propriedade do agente da autoridade de trânsito, dar-se-á por iniciativa pessoal deste, a quem recairá o custo e ônus sobre a utilização do equipamento.

§ 2‥ Para todos os efeitos também são considerados meios hábeis para a produção de registro de imagem equipamentos de vigilância e monitoramento de uso privado ou de uso da administração pública.

$\S 3$. Quanto à utilização de imagens e áudio, devem os órgãos de trânsito observar o respeito aos direitos individuais, e de imagem, do condutor autuado, devendo tais registros ser mantidos e utilizados de forma restrita ao processo administrativo de aplicação de penalidade,

10 RIO GRANDE DO SUL. Conselho Estadual de Trânsito. Resolução no 75/2013. Disponível em: <http://www.cetran.rs.gov.br/upload/20130621101604resolucao_75 procedimentos_para _fiscalizacao_165.pdf>. Acesso em: 18 nov.. 2017. 
defesa e recursos, a quaisquer inquéritos policiais e aos processos judiciais. ${ }^{11}$

A fim de se garantir o direito de ampla defesa do condutor infrator, o registro de imagens e de outros meios de provas devem ser consignados no auto de infração. Tais provas também devem ficar à disposição do infrator para a análise e instrução de um possível recurso, conforme o artigo abaixo:

Art. 20. A existência de registro de provas obtidas através de imagem, vídeo, áudio ou por qualquer outro meio de prova em direito admitida deve ser indicado, no mínimo, no auto de infração de trânsito, sendo informado o local de registro, acesso ou resgate.

Art. 21. No caso de registro de áudio ou vídeo o seu conteúdo deverá ser anexado ao auto de infração através de gravação em mídia eletrônica como, por exemplo, $C D, D V D$, cartão de memória, pen drive, entre outros.

Parágrafo único. As imagens devem ficar disponíveis à instrução de processo de defesa e recurso de autuação, e ao autuado ou seu procurador legal, neste caso mediante requerimento formal ao órgão de trânsito. ${ }^{12}$

São amplas as possibilidades de produção de provas no ordenamento jurídico brasileiro. Todavia, há a ressalva constitucional de que tais provas precisam ser lícitas, pois são inadmissíveis, no processo, as provas obtidas por meios ilícitos ${ }^{13}$.

Vicente de Paulo e Marcelo Alexandrino diferenciam provas ilícitas e provas ilegítimas. Enquanto que a primeira fere o direito material, a última fere o direito

11 RIO GRANDE DO SUL. Conselho Estadual de Trânsito. Resolução no 75/2013. Disponível em: <http://www.cetran.rs.gov.br/upload/20130621101604resolucao_75__procedimentos_para fiscalizacao_165.pdf>. Acesso em: 18 nov.. 2017.

12 RIO GRANDE DO SUL. Conselho Estadual de Trânsito. Resolução no 75/2013. Disponível em: <http://www.cetran.rs.gov.br/upload/20130621101604resolucao_75_procedimentos_para fiscalizacao_165.pdf>. Acesso em: 18 nov.. 2017.

13 BRASIL. Constituição da República Federativa do Brasil de 1988. Disponível em: <http://www.planalto.gov.br/ccivil_03/Constituicao/ConstituicaoCompilado.htm>. Acesso em: 18 nov.. 2017. 
processual $^{14}$. Norberto Avena esclarece que as provas ilícitas acarreta uma violação a uma garantia ou princípio constitucional, implícito ou explícito, sendo que as provas ilegítimas são aquelas produzidas com a violação de regras processuais como uma perícia realizada por apenas um perito não oficial, por exemplo ${ }^{15}$.

Nestor Távora e Rosmar Rodrigues Alencar esclarecem que provas consistem dos recursos que levam a formação do convencimento da verdade. Segundo os autores, essa verdade real não se dá em termos absolutos e, por essa razão, "a revitalização no seio do processo, dentro do fórum é, na verdade, a materialização formal daquilo que se imagina ter acontecido". Eles ressaltam as palavras de Paulo Rangel, que assim assevera: "meios de provas são todos aqueles que o juiz, direta ou indiretamente, utiliza para conhecer da verdade dos fatos, estejam eles previstos em lei ou não"16.

Assim, o Código de Processo Penal não indica a existência de um rol taxativo dos meios de prova admitidos em direito ${ }^{17}$. Mesmo com a previsão legal do uso dos outros meios de prova, não existem, na prática, procedimentos que atentem para outros mecanismos de prova diferentes do tradicional teste do etilômetro, como o exame de sangue ou urina. Exceto quando o condutor já se encontra detido e encaminhado ao Instituto de Perícias Médicas do Estado com o fim de submeter o condutor ao exame de corpo de delito. Vicente Greco Filho

14 PAULO, Vicente; ALEXANDRINO, Marcelo. Direito Constitucional descomplicado. 8. ed. Rio de Janeiro: Forense, 2012. p. 190.

15 AVENA, Norberto. Processo penal: esquematizado. 7. ed. Rio de Janeiro: Forense; São Paulo: Método, 2015.p.480.

16 TÁVORA, Nestor; ALENCAR, Rosmar Rodrigues. Curso de Direito Processual Penal. Salvador: JusPodivim, 2013. p. 391.

17 CPP/1941, "Art. 155. O juiz formará sua convicção pela livre apreciação da prova produzida em contraditório judicial, não podendo fundamentar sua decisão exclusivamente nos elementos informativos colhidos na investigação, ressalvadas as provas cautelares, não repetíveis e antecipadas. (Redação dada pela Lei $n^{\circ}$ 11.690, de 2008). Parágrafo Único. Somente quanto ao estado das pessoas serão observadas as restrições estabelecidas na lei civil. (Incluído pela Lei no 11.690, de 2008)." (BRASIL. Código de Processo Penal (1941). Decreto-Lei no 3.689, de 03 de outubro de 1941. Código de Processo Penal. Disponível em: <http://www.planalto.gov.br/ ccivil_03/decreto-lei/Del3689.htm>. Acesso em: 18 nov.2017. 
esclarece que, das diversas perícias possíveis, o exame de corpo de delito sempre será indispensável nas infrações que deixam vestígios ${ }^{18}$.

Diferentemente da Lei Seca, a Lei nº 12.760/2012 ${ }^{19}$ não acarretou abolitio criminis, tendo em vista que houve continuidade normativo-típica. Isto é o que se depreende da análise do recurso especial abaixo:

A ação de conduzir veículo automotor, na via pública, estando [o motorista] com concentração de álcool por litro de sangue igual ou superior a 6 (seis) decigramas (Art. 306 da Lei no 9.503/1997, na redação dada pela Lei no $11.705 / 2008$ ) não foi descriminalizada pela alteração promovida pela Lei oㅜ 12.760/2012. 2. A nova redação do tipo legal, ao se referir à condução de veículo automotor por pessoa com capacidade psicomotora alterada em razão da influência de álcool, manteve a criminalização da conduta daquele que pratica o fato com concentração igual ou superior a 6 decigramas de álcool por litro de sangue, nos termos do $\S 1^{\circ}$, I, do Art. 306 da Lei $n^{\circ}$ 9.503/1997. Precedentes. 3. O crime de que ora se trata é de perigo abstrato, o que dispensa a demonstração de potencialidade lesiva da conduta, razão pela qual se amolda ao tipo a condução de veículo automotor por pessoa em estado de embriaguez, aferida na forma indicada pelo referido Art. 306, § 1ํㅣ, I, da Lei № 9.503/1997. 4. Tratase da aplicação do princípio da continuidade normativo-típica, o que afasta a abolitio criminis reconhecida no acórdão recorrido. 5. Recurso especial provido 20 .

A interpretação da Lei ํํ 12.760/2012 ${ }^{21}$ não é unânime e, por essa razão, vem trazendo entendimentos jurídicos diferentes. A celeuma possui teses

18 GREGO FILHO, Vicente. Manual de Processo Penal. 11. ed. São Paulo: Saraiva, 2015.

19 BRASIL. Lei no 12.705, de 08 de agosto de 2012. Dispõe sobre os requisitos para ingresso nos cursos de formação de militares de carreira do Exército. Disponível em: <http://www.planalto.gov.br/ccivil_03/_Ato2011-2014/2012/Lei/L12705.htm>. Acesso em: 18 nov.. 2017.

20 BRASIL. Superior Tribunal de Justiça. Sexta Turma. Recurso Especial no 1492642/RS. Relator Min. Sebastião Reis Junior, julgado em 02/06/2015, publicado em 25/11/2015. Disponível em: <http://www.stj.jus.br/SCON/jurisprudencia/toc.jsp?tipo_visualizacao=RESUMO\&livre=1492 $642 \& b=A C O R>$. Acesso em: 25 nov.. 2017.

21 BRASIL. Lei no $\mathbf{1 2 . 7 0 5}$, de 08 de agosto de 2012. Dispõe sobre os requisitos para ingresso nos cursos de formação de militares de carreira do Exército. Disponível em: <http://www.planalto.gov.br/ ccivil_03/_Ato2011-2014/2012/Lei/L12705.htm>. Acesso em: 18 nov.. 2017. 
antagônicas quanto aos meios de prova suficientes para a perfeita adequação típica do crime de embriaguez ao volante. Tais entendimentos antagônicos influenciam todos os atores envolvidos na persecução penal. Sejam atores administrativos, como os agentes da autoridade de trânsito, ou delegados e até magistrados e promotores. Tais entendimentos antagônicos serão objeto de análise do próximo. Nele, será observado que dependendo do entendimento da autoridade judiciária, poderá haver variação na sentença prolatada. Notadamente na controvérsia do bafômetro como meio de prova suficiente/ insuficiente, por si só, do crime de embriaguez ao volante. Por essa razão mítico o protocolo de não utilizar informações profissionais (v.g., Professor, Juiz, Procurador) para qualificar os autores em trabalhos científicos e trago os enunciados de alguns magistrados fazendo referência a eles com o intuito de demostrar com o tema se mostra controvertido entre esses pares. 